\title{
Rotation and Position Encoder from a Mark of Radial Fringe in Color-RGB by using Phase Shifting
}

\section{Codificador de Posición y Rotación a partir de una Marca de Franjas Radiales en Color-RGB Usando Phase Shifting}

\author{
Carlos Hugo Arámbula Páez ${ }^{1}$, Martha Lucia Molina Prado ${ }^{1}$, Néstor Alonso Arias \\ Hernande ${ }^{1 *}$ \\ 1. Grupo de Óptica Moderna, Departamento de Física y Geología, Universidad de Pamplona, Colombia \\ ${ }^{(*)}$ E-mail: nesariher@unipamplona.edu.co
}

Received: 02/12/2016 Accepted: 18/12/2017

DOI: $10.7149 /$ OPA.51.1.49052

\begin{abstract}
:
In this work, a method which seeks to locate a radial-color mark attached to the object using the high sensitivity of the phase to determine the position spatial and angular with subpixel resolution due to movement of an object in a 2D scene is presented. The reference pattern is formed by a regular distribution with radially symmetrical of color-RGB fringes. The reconstruction of the absolute phase associated to the fringes allows the location the precise center of the mark and it finds position of the object with sub-pixel resolution. The reconstruction of absolute phase associated with the fringes using the phase shifting technique at three-frame and a development phase algorithm is calculated. A transformation of coordinates and a least squares adjustment is realized giving a function for to extract the center of the reference pattern. Experimental results of measurements of position, displacement and orientation with subpixel resolution is presented, as well as the description of the process for system optimization.
\end{abstract}

Key words: Fourier Transform, unwrapping, Tracking, Positioning, Phase Shifting.

\section{RESUMEN:}

En este trabajo, se presenta un método que pretende localizar una marca radial a color adherida al objeto, usando la alta sensibilidad de la fase para determinar con resolución subpixel la posición espacial y angular debida al movimiento de un objeto en una escena 2D. El patrón de referencia está constituido por una distribución regular con simetría radial de franjas a color. La reconstrucción de la fase absoluta asociada a las franjas permite la localización precisa del centro de la mira, que conlleva a la determinación de la posición del objeto con resolución subpixel. La reconstrucción de la fase absoluta asociado a las franjas se calcula utilizando la tecnica phase shifting a tres imagenes y un algoritmo de desenvolvimiento de la fase. Posteriormente se realiza una transformación de coordenadas y un ajuste por minimos cuadrados, obteniendo una función, que permite extraer el centro del patrón de referencia. Se presentan resultados experimentales de medidas de posición, desplazamiento y orientación con resolución subpixel, así como, la descripción del procedimiento para la optimización del sistema.

Palabras clave: Transformada de Fourier, Desenvolvimiento, Rastreo, Posicionamiento Corrimiento de Fase.

\section{REFERENCES AND LINKS / REFERENCIAS Y ENLACES}

[1] L. A. Galindo, C. A. Ramírez, J. E. Meneses, J. G. Barrero, Medida simultánea de rotaciones y traslaciones de un objeto en el plano a partir de la información de fase de una rejilla radial, Iteckne, Vol. 92 (2012).

[2] J. Meneses, D. Acevedo, "Sistema de posicionamiento global de un objeto en el espacio usando visión estéreo de alta resolución,” Óptica Pura y Aplicada, Vol. 453 307-313 (2012). 
[3] K.S. Yen, M.M. Ratnam, "Comparison of in-plane displacement measurement from circular grating moiré fringes using Fourier transformation and graphical analysis," Optics and Lasers in Engineering 50, 687-702, (2012).

[4] M. Takeda, H. Ina, S. Kobayashi, "Fourier-transform method of fringe-pattern analysis for computerbased topography and interferometry" J. Opt. Soc. Am. 72, 156-160 (1982).

[5] Sandoz P., Jacquot M. "Lensless vision system for in-plane positioning of a patterned plate with subpixel resolution,” J. Opt. Soc. Am. 274 (2011).

[6] Kjell J. Gasvik. Optical metrology, Third Edition. Spectral vision AS, Trond- hein, Norway (2002).

[7] Nestor A. Arias H., Patrick Sandoz, Jaime E. Meneses, Miguel A. Suarez, Tijani Gharbi, “3d Localization Of A Labeled Target By Means Of A Stereo Vision Configuration With Subvoxel Resolution," Optics Express, Vol. 18, 23 24152-24162, (2010).

\section{Introduction}

Position and displacement measurement with high accuracy and resolution have been widely studied and applied in various fields of science and engineering. Also have been proposed several devices that measure the position and rotation of an object with high precision through techniques optical, of radiofrequency, digital image processing for localization of marks between other.

In this paper a method in the field of the image processing is developed, which aims to locate a mark. It is uses the high sensitivity of the phase with respect to displacement, allowing measure the position and displacement of an object in a 2D scene, with high accuracy and resolution. This method is based on priori knowledge of the association between the phase of the reference pattern and the displacement of the object, inherent property of the Fourier transform $[1,2,3,7]$. The reference pattern or target consists of a intensity periodic distribution in color RGB, to be will constructed with shifting in the phase in each plane of color according to technique of phase shifting at three image [6], where the capture of a color target and the phase shifting treatment, is the main difference compared with other works of the radial targets $[1,3,7]$. The phase is obtained by performing the corresponding calculation according to the technique of three images, one image per each color plane, obtained in a single capture. The phase obtained is wrapped between $-\pi$ and $\pi$, it is necessary to apply a classical phase unwrapping algorithm [4]. The reconstructions of the absolute phase associated at fringes system allows precise location of the center of the target that involve determine the positioning of the object with precision subpixel. The displacements in plane are calculated from two consecutive positions. We will describe this work in detail in the following sections.

\section{Experimental Setup}

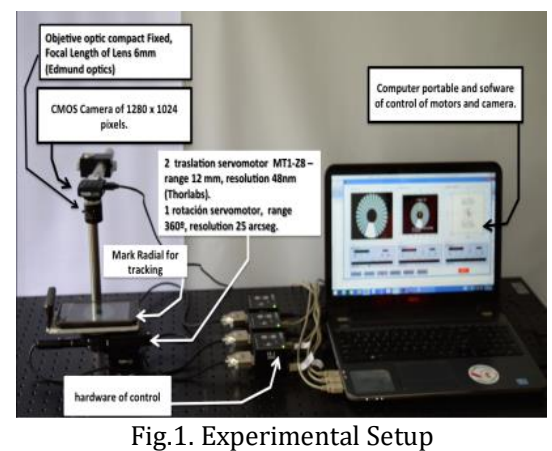

The experimental setup (fig.1) is composed of a digital camera type CMOS of 1280x1024 pixels, a compact fixed objective optics, of focal length $6 \mathrm{~mm}$ (Edmund optics), 2 translation servomotor MT1-Z8, of range $12 \mathrm{~mm}$ and resolution $48 \mathrm{~nm}$ (Thorlabs), 1 rotation servomotor of range 360 degree and resolution of 25 arcseg. The CMOS camera obtains the image of the Mark of radial fringe in color. The mark of radial fringe in color is formed by a system of fringe in each color plane RGB and out of phase complying with the method of Phase Shifting to three images. The mark of radial fringe in color is a circular ring of smaller radius $r_{\min }=3.7 \mathrm{~mm}$ and greater radius $r_{\max }=8.6 \mathrm{~mm}$, in which the fringes are in color and has a white circular section. The field of view of the system is $56.24 \mathrm{~mm} \times 44.99 \mathrm{~mm}$ and the interpixel distance is 43.95 micrometers. 


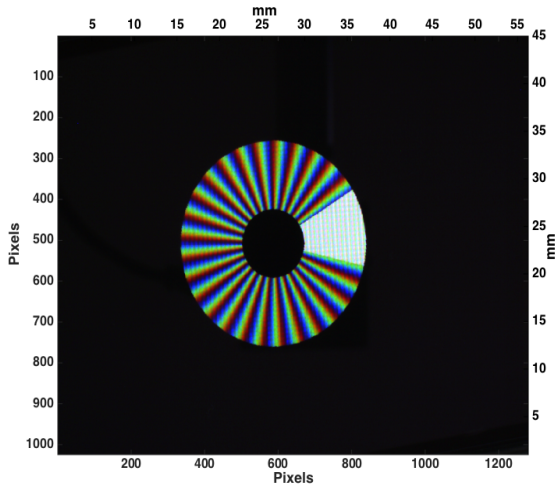

Fig.2. Image at color of the mark captured and the observation field.

\section{Principle of Method}

\section{3.a. Segmented}

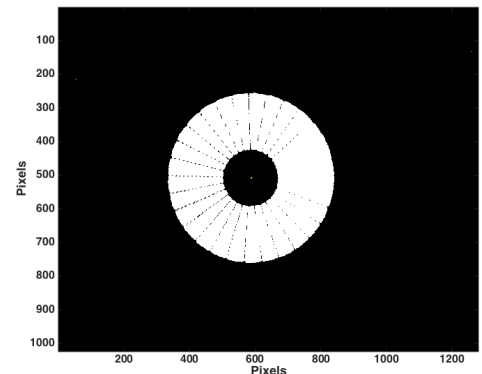

Fig.3. Binary image obtained after of binarization

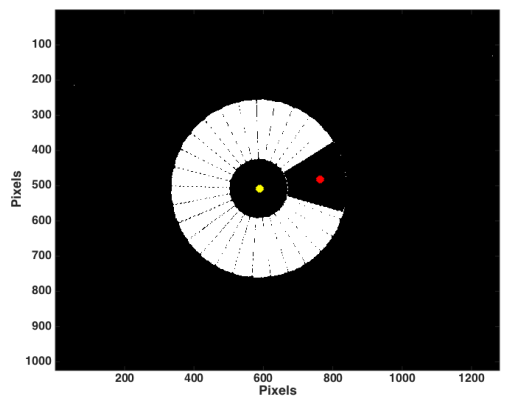

Fig.5. Removal of the wedge from the initial binary image and draw the centroid of the entire binary image and that of the wedge.

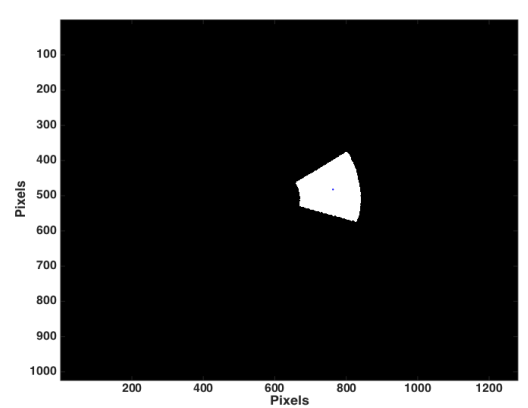

Fig.4. Segmentation of the wedge.

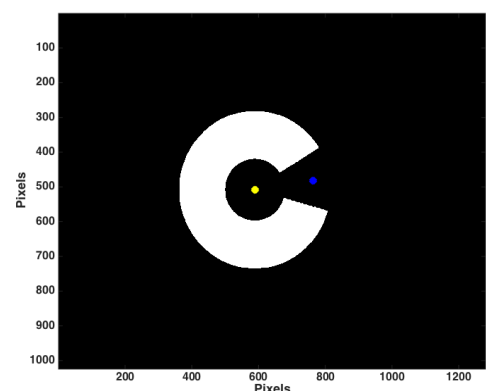

Fig.6. An binary mask is constructed and draw the centroid of the entire binary image and that of the wedge.

In fig. 2, we apply a threshold in each color plane $(0.2 \mathrm{R}, 0.4 \mathrm{G}, 0.2 \mathrm{~B})$ and performing logical operation $\mathrm{OR}$ between them, a binary image fractioned with different areas (fig.3) is obtained. It is necessary to use as a selection criterion the largest area of objects present in the previous image to segment the wedge and calculate the centroid of the wedge (fig.4). The centroid of the all image is calculated for the purpose of having it as a reference for performing the coordinate transformation (fig.5 and fig.6). In fig. 5 shows the removal of the wedge from the initial binary image and you can see the centroid of the all-binary image and of the wedge. A binary mask is constructed by taking the smallest and largest radius present in the fig.3. The previous result is multiplied with the negative of fig. 4 to obtain the region of interest in which the color fringes are present, fig.6.

\section{3.b. Calculation of the phase}

The technique of obtaining the phase is Phase Shifting to three images, it shows the profile on the image captured in the three color planes RGB with their corresponding phase shift $\frac{\pi}{4}, \frac{3 \pi}{4} y \frac{5 \pi}{4}$ (fig.2 and fig.7). 
The Phase Shifting algorithm is applied to three images, where each color plane corresponds to one IR, IG, and IB image.

$$
\phi=\tan ^{-1}\left(\frac{I_{B}-I_{G}}{I_{R}-I_{G}}\right)
$$

where $\phi$ is the phase obtained, $I_{R, G, B}$ are the color planes.

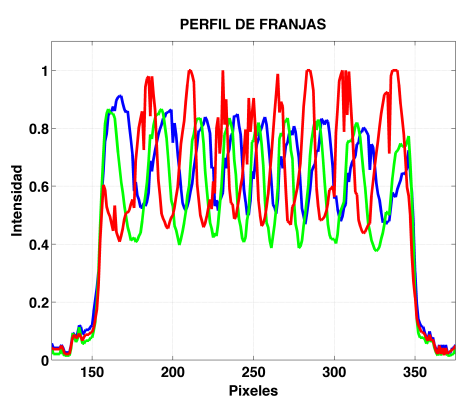

Fig.7. Profile of the image captured in the three color planes RGB.

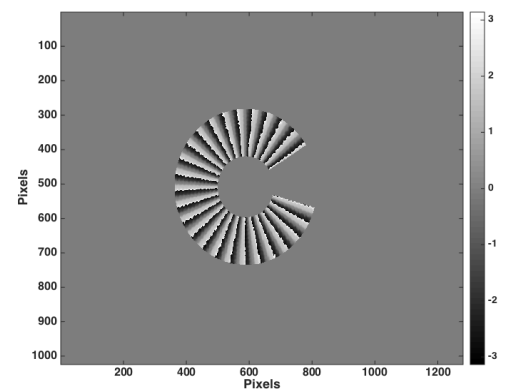

Fig.9. Phase of interest obtained after multiplying by the binary mask.

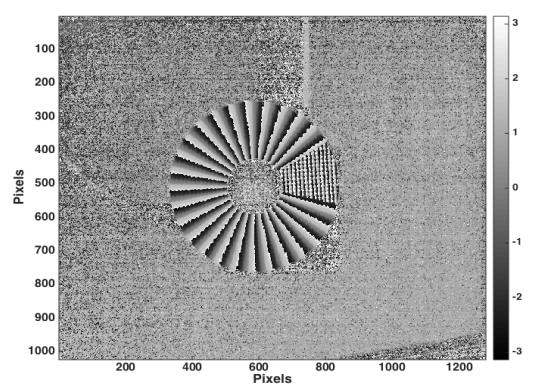

Fig.8. Phase obtained for the phase shifting.

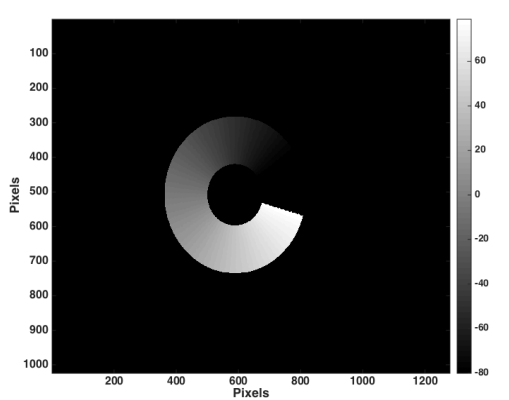

Fig.10. Phase unwrapping.

The phase image wrapped between $-\pi$ and $\pi$ is obtained (fig. 8). As the phase is discontinuous and it is wrapped it is necessary to apply an clasic unwrapping algorithm. This algorithm only working the phase in the zone of interest, with the help of the mascara built (fig.9). The applied unwrapping algorithm have a start point in the arc center of the working mask. This remove the jumps of $2 \pi$ present in the phase(fig.10).

\section{3.c. Position, Displacement and Rotation Measurement}

A polar coordinate transformation to cartesian is performed using the centroid calculated in the initial mask(fig.11). Also, adding the reference angle (from the wedge) a correction is made, so that all the phase values are in a single region(fig.12), as of these values of phase an equation of a plane by least squares is obtained:

$$
a \theta+b r+c=\phi
$$

where $\theta$ is the angle, $\mathrm{r}$ is radius and $\phi$ is the phase.

From equation 2, an angle can be calculated for a specified phase and radius value. Using two arbitrary radiii values within the region and the phase values of $0 \pi$ and $15 \pi$, we obtain four points, with which once the transformation of coordinates is made, two lines are constructed with points of equal angles. When the intersection of these two lines is made then the center of the mark is obtained (fig.13, fig.14). The angle of the mark corresponds to the line with phase value 0 . The center of the mark and its orientation is calculated automatically. 


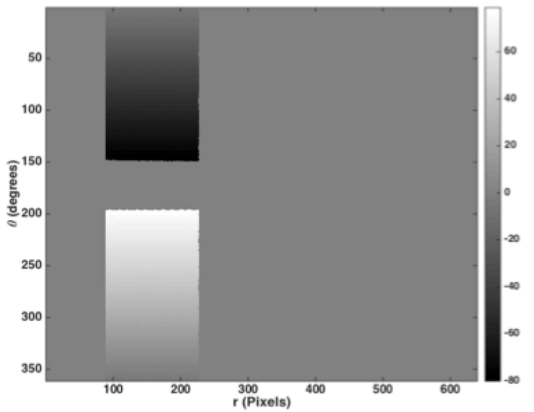

Fig.11. Cartesian to polar coordinate transformation.

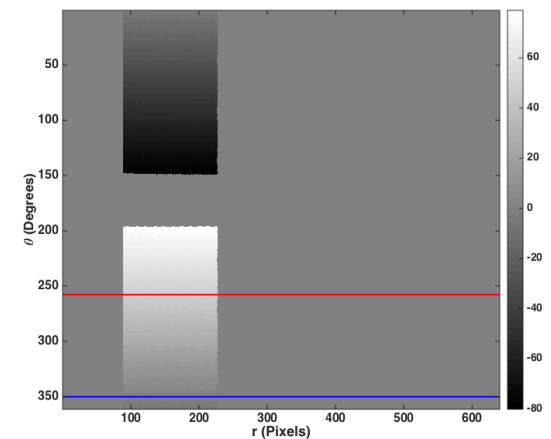

Fig.13. Selection of the two arbitrary radii within the region and the phase of 0 pi and 15 pi for calculate of four points of the position.

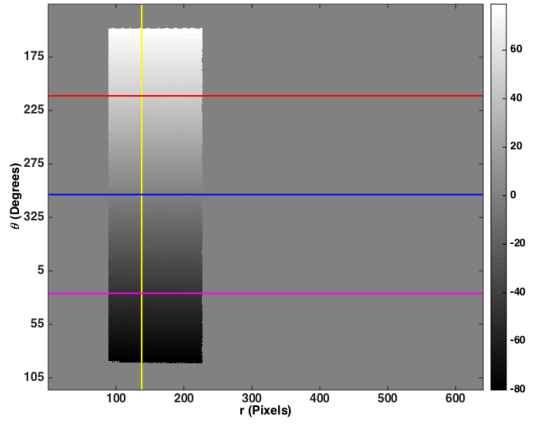

Fig.12. Correction of the location of phase values and selection of phase and radiii values for calculate of position and angle.

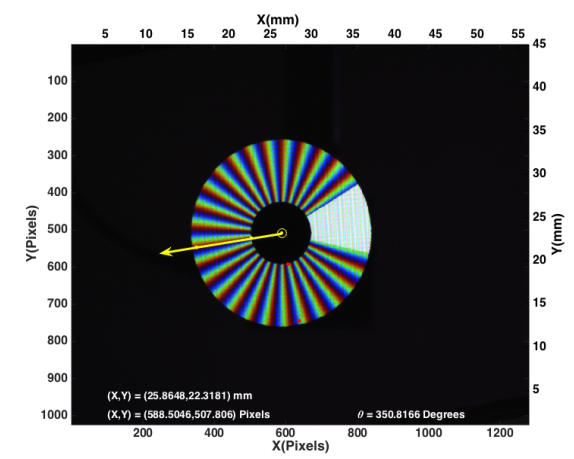

Fig.14. The calculated four points that allow to construct two lines, in such a way, that its intersection is the center of the mark and the orientation is one of them.

\section{3.d. Results and Discussions.}

The resolution of the mark versus the gain of the camera, the frequency of the fringes and the area of the mark in the field of vision were evaluated (fig.15). This it allows to select the characteristics of the brand with more precision. The resolution of the mark in each experiment is obtained after computing 100 measurements without displacement. This presents a resolution of 1 micron approximately, equivalent to 3 standard deviations (fig.16). The system can measure angles in a range of 360 degrees (fig.17) with a resolution of approximately 0.005 degrees, equivalent to 3 standard deviations. The system can perform subpixel displacement measurement. In the image was traced the GOM signal inside a pixel (fig.18).

\section{Conclusions}

In this paper, a method of sub-pixel resolution for measuring the positioning and rotation in plane of an object are implemented using a periodic array of fringe at color. This mark is formed by a strip system in each color plane RGB and out of phase agree with the method of Phase Shifting to three images. The results show that is possible to determine the position and angular displacement of an object in plane, with subpixel precision. The system resolution depends on the specific characteristics of the sampling, fringes number, noise and gain of the camera. Similarly, the effect of to add a wedge on the mark allows for a rotation of $360^{\circ}$. A maximum resolution of approximately 0.3 microns is observed for when the camera gain is $70 \%$ and the resolution behavior of the system versus the frequency of the fringes is that the error increases when the frequency increases, as well as when the area that occupies the mark in the field of vision is greater the resolutionn increases. The implemented subpixel resolution system allows to perform calculation of position and orientation in plane using a radial mark to color adhered to object. In the system a technique known as phase shifting to 3 images with only one captured image is used. 
ÓPTICA PURA Y APLICADA

www.sedoptica.es
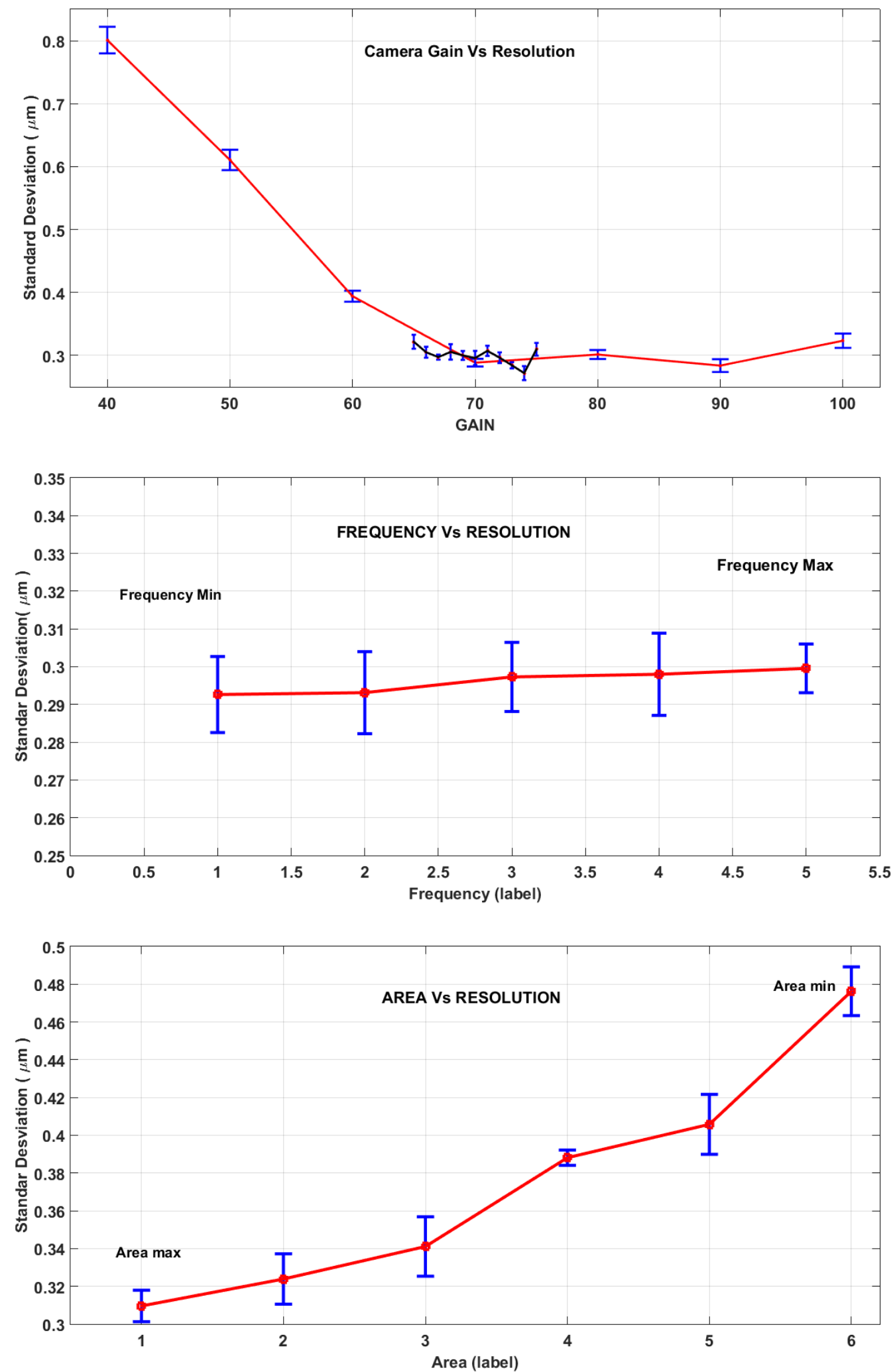

Fig.15. Accuracy of the brand versus the gain of the camera, the frequency of the stripes and the area of occupation of the mark in the field of visión. 


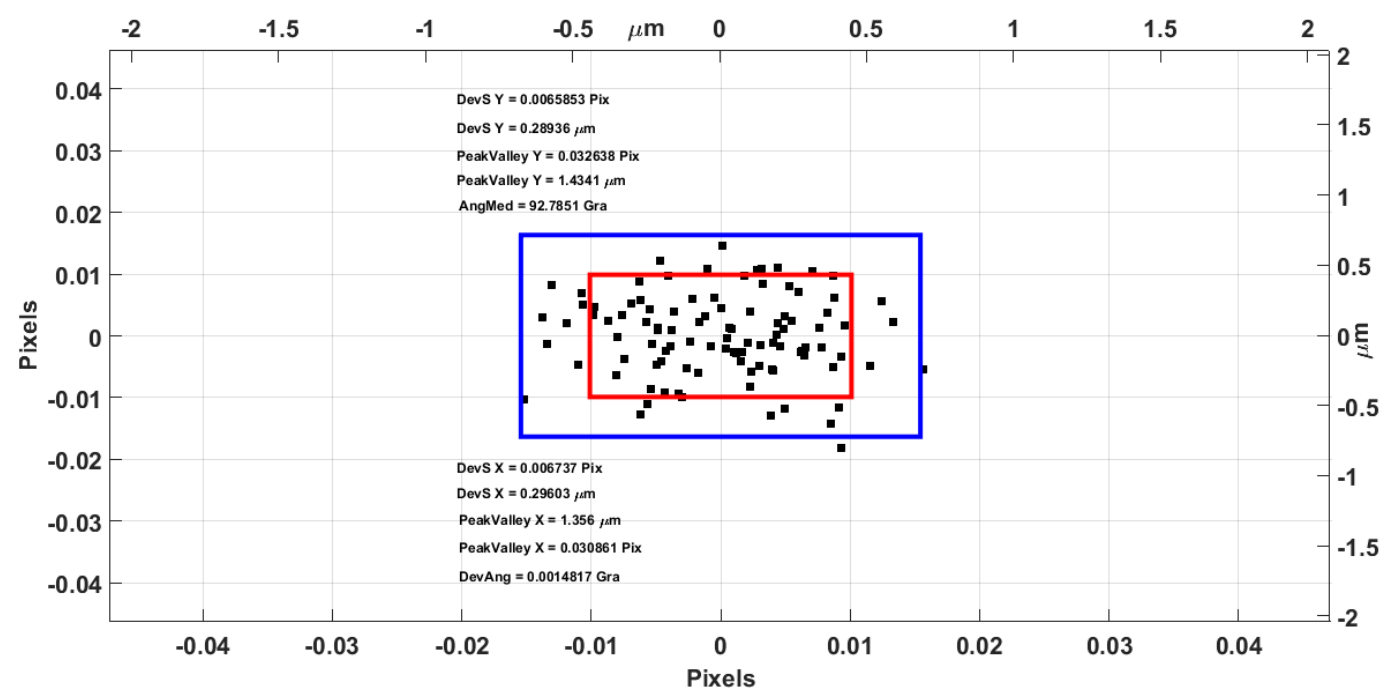

Fig.16. Computing 100 measurements without displacement.

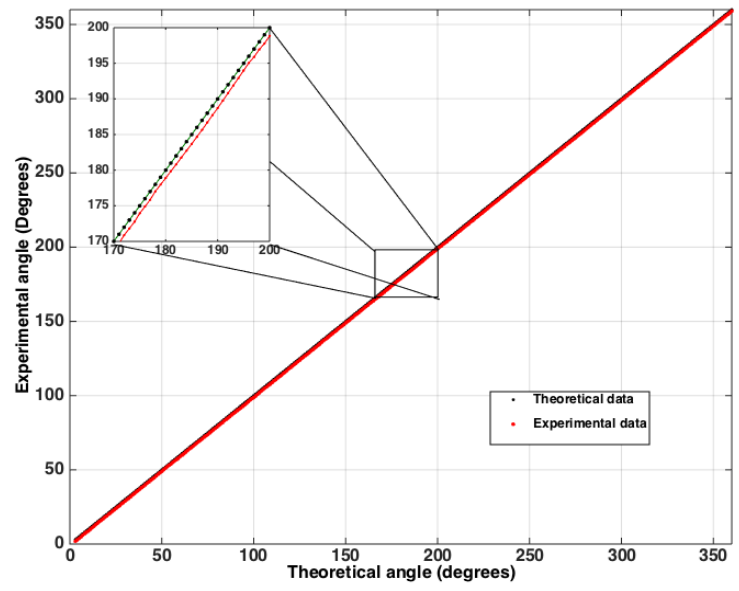

Fig.17. Measurements of the angles in a range of 360 degrees.

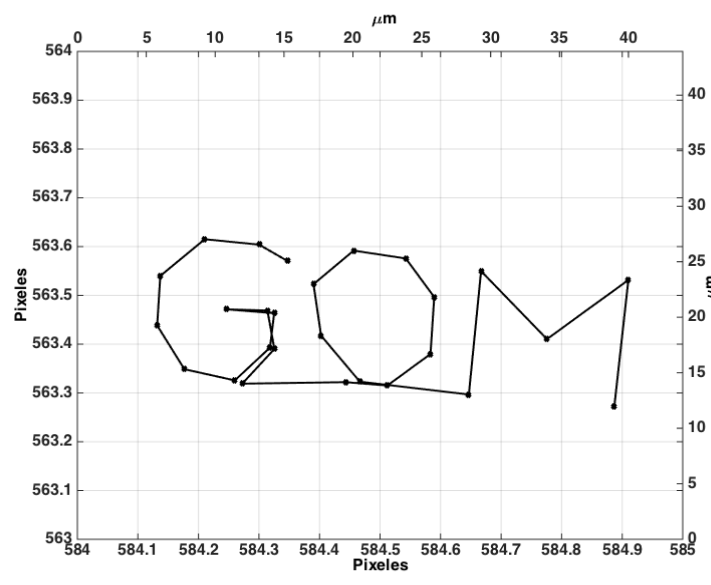

Fig.18. Tracking of the mark within one pixel.

\section{Acknowledgements}

The authors are grateful to the Vice-Rectory of Research of the University of Pamplona (COL) for financial support to participate in IX Ibero-American Optical Meeting and XII Ibero-American Meeting of Optics, Lasers and Applications (RIAO / OPTILAS), Pucón, Chile 2016. These results are part of The Research Projects PR130-00-013 (GA150-BP-II-2013-2.1.2.2.1), registered at the Vice-Rectory of Research of the University of Pamplona and these results are part of the research projects of semillero COUP. This work were presented at the XII Ibero-American Meeting of Optics, Lasers and Applications (RIAO / OPTILAS), Pucón, Chile 2016. 